\title{
Functional status and quality of life 12 months after discharge from a medical ICU in healthy elderly patients: a prospective observational study
}

Emilio Sacanella $a^{1,2^{*}}$, Joan Manel Pérez-Castejón ${ }^{1}$, Josep Maria Nicolás ${ }^{2,3}$, Ferran Masanés ${ }^{1,2}$, Marga Navarro ${ }^{1,2}$, Pedro Castro ${ }^{2,3}$ and Alfonso López-Soto ${ }^{1,2}$

\begin{abstract}
Introduction: Long-term outcomes of elderly patients after medical ICU care are little known. The aim of the study was to evaluate functional status and quality of life of elderly patients 12 months after discharge from a medical ICU.

Methods: We prospectively studied 112/230 healthy elderly patients ( $\geq 65$ years surviving at least 12 months after ICU discharge) with full functional autonomy without cognitive impairment prior to ICU entry. The main diagnoses at admission using the Acute Physiology and Chronic Health Evaluation III (APACHE III) classification diagnosis and length of ICU stay and ICU scores (APACHE II, Sepsis-related Organ Failure Assessment (SOFA) and OMEGA) at admission and discharge were collected. Comprehensive geriatric assessment included the presence of the main geriatric syndromes and the application of Lawton, Barthel, and Charlson Indexes and Informant Questionnaire on Cognitive Decline to evaluate functionality, comorbidity and cognitive status, respectively. The EuroQol-5D assessed quality of life. Data were collected at baseline, during ICU and ward stay and 3,6 and 12 months after hospital discharge. Paired or unpaired T-tests compared differences between groups (continuous variables), whereas the chi-square and Fisher exact tests were used for comparing dichotomous variables. For variables significant $(P \leq 0.1)$ on univariate analysis, a forward multiple regression analysis was performed.
\end{abstract}

Results: Only $48.9 \%$ of patients (mean age: $73.4 \pm 5.5$ years) were alive 12 months after discharge showing a significant decrease in functional autonomy (Lawton and Barthel Indexes) and quality of life (EuroQol-5D) compared to baseline status $(P<0.001$, all). Multivariate analysis showed a higher Barthel Index and EQ-5D vas at hospital discharge to be associated factors of full functional recovery $(P<0.01$, both). Thus, in patients with a Barthel Index $\geq 60$ or EQ-5D vas $\geq 40$ at discharge the hazard ratio for full functional recovery was 4.04 (95\% Cl: 1.58 to $10.33 ; P=0.005)$ and 6.1 (95\% Cl: 1.9 to $19.9 ; P<0.01$ ), respectively. Geriatric syndromes increased after ICU stay and remained significantly increased during follow-up $(P<0.001)$

Conclusions: The survival rate of elderly medical patients 12 months after discharge from the ICU is low (49\%), although functional status and quality of life remained similar to baseline in most of the survivors. However, there was a two-fold increase in the prevalence of geriatric syndromes.

\footnotetext{
* Correspondence: esacane@clinic.ub.es

${ }^{1}$ Geriatric Unit, Department of Internal Medicine Hospital Clínic of Barcelona,

Villarroel, 170, Barcelona 08036, Spain

Full list of author information is available at the end of the article
} 


\section{Introduction}

Admission of elderly patients to the intensive care unit (ICU) occurs frequently in Western countries [1,2] and this situation will probably grow in the near future [2]. In spite of this, many physicians have doubts as to whether elderly subjects are good candidates for ICU care because of the apparently, albeit possibly false, poor long-term outcomes (such as mortality, functional autonomy and quality of life) after critical care in this population [3-12]. It is especially important to confirm or to rule out this hypothesis in healthy elderly subjects with a good pre-morbid status before ICU admission and who have a theoretical long life expectancy prior to critical care admission (up to 20 years) [13]. Indeed, to our knowledge no previous study has been focussed on this specific population of elderly medical patients.

Up to now, several papers have evaluated the outcomes of elderly subjects after ICU care; however, the results obtained have been very heterogeneous [1-3,5,7]. In addition, some intensive care physicians have suggested that lower treatment intensity in elderly compared to younger subjects could be the cause of worse outcomes in these individuals [4] with recent higher treatment intensity applied to older subjects having been associated with better outcomes [14].

Short- and long-term mortality of elderly patients after ICU care is reported to be between 11 to $38 \%$ and 22 to $69 \%$, respectively, whereas functional autonomy and quality of life may be moderately decreased in 10 to $60 \%$ of subjects $[1,2,5,12,15]$. This great heterogeneity in the results obtained may be due to significant differences in the methodology used and also in the patients (age, pre-morbid status, main diagnosis at ICU entry) and the type of ICU (surgical or medical) studied, making it difficult to obtain conclusions about the outcomes of specific subpopulations of elderly subjects after ICU discharge [3,6,8-10,16]. Boumendil et al. [1] recently suggested that to answer this question, specific groups of critically ill elderly patients should be prospectively studied to identify those with a better prognosis.

Most studies on the outcome of elderly patients after ICU care have been restricted mainly to surgical patients $[6,8,9,11]$, although medical ICU patients are known to usually have a worse prognosis $[3,6,8,9]$. Thus, in a recent series on this issue only 11 subjects (5\%) were medical patients [11]. In summary, the results in the literature are heterogeneous, making it difficult to achieve recommendations for decision making related to the admission of elderly subjects to the ICU, especially in those with a good pre-morbid status with a medical condition.

Therefore, we embarked on a prospective observational study in a series of healthy community-dwelling elderly patients with a good pre-morbid status prior to
ICU admission to evaluate the long-term outcomes in terms of functional and cognitive status and quality of life after non-elective medical ICU admission.

\section{Materials and methods \\ Patient selection}

We performed a prospective observational study in an eight-bed medical ICU. We enrolled patients $\geq 65$ years living at home with full autonomy (Barthel Index (BI) $\geq 70$ ), without cognitive impairment, and who were nonelectively admitted to the ICU for a medical condition. Patients admitted to the ICU after cardiac arrest or with end-stage disease were excluded. A total of 230 patients were enrolled. Of these, 160 were discharged alive from hospital, 48 of whom died after discharge and the remaining 112 patients (49\%) were alive one year later and were evaluated as described below (Figure 1). All the patients were enrolled in the first 24 to 48 hours after ICU admission. The participants or a close relative gave informed consent to participate in the study which was performed in accordance with the ethical standards established in the 1964 Declaration of Helsinki. The institutional review board of Hospital Clínic, Barcelona, Spain, approved the study protocol.

\section{ICU data}

The main diagnoses at admission were collected using the Acute Physiology and Chronic Health Evaluation III (APACHE III) classification diagnosis and length of ICU stay. Severity of illness, organ dysfunction and therapeutic intensity were measured using the APACHE II [17], Sepsis-related Organ Failure Assessment (SOFA) [18] and OMEGA [19] scores, respectively. The OMEGA score is used to assess therapeutic intensity in the ICU and is constituted of 47 diagnostic and therapeutic parameters each with an assigned value; the total OMEGA score is obtained by the sum of these values throughout ICU stay.

\section{Comprehensive geriatric assessment (CGA) and Quality of Life (QOL) evaluation}

A CGA including functional, neuropsychological, comorbidity, QOL evaluation and geriatric syndromes assessment were performed in all the patients. Functional evaluation included assessment of autonomy in instrumental and basic activities of daily life (IADL and ADL, respectively) which were evaluated with the Lawton Index (LI) [20] and Barthel Index [21], respectively. Both are quantitative scales ranging from 0 to 8 (LI) and from 0 to 100 (BI). Scores of 8 and 100 points, respectively, denote full autonomy in IADL and ADL. Cognitive function was assessed with the Informant Questionnaire on Cognitive Decline in the Elderly (IQCODE) or the Minimental Status Evaluation 


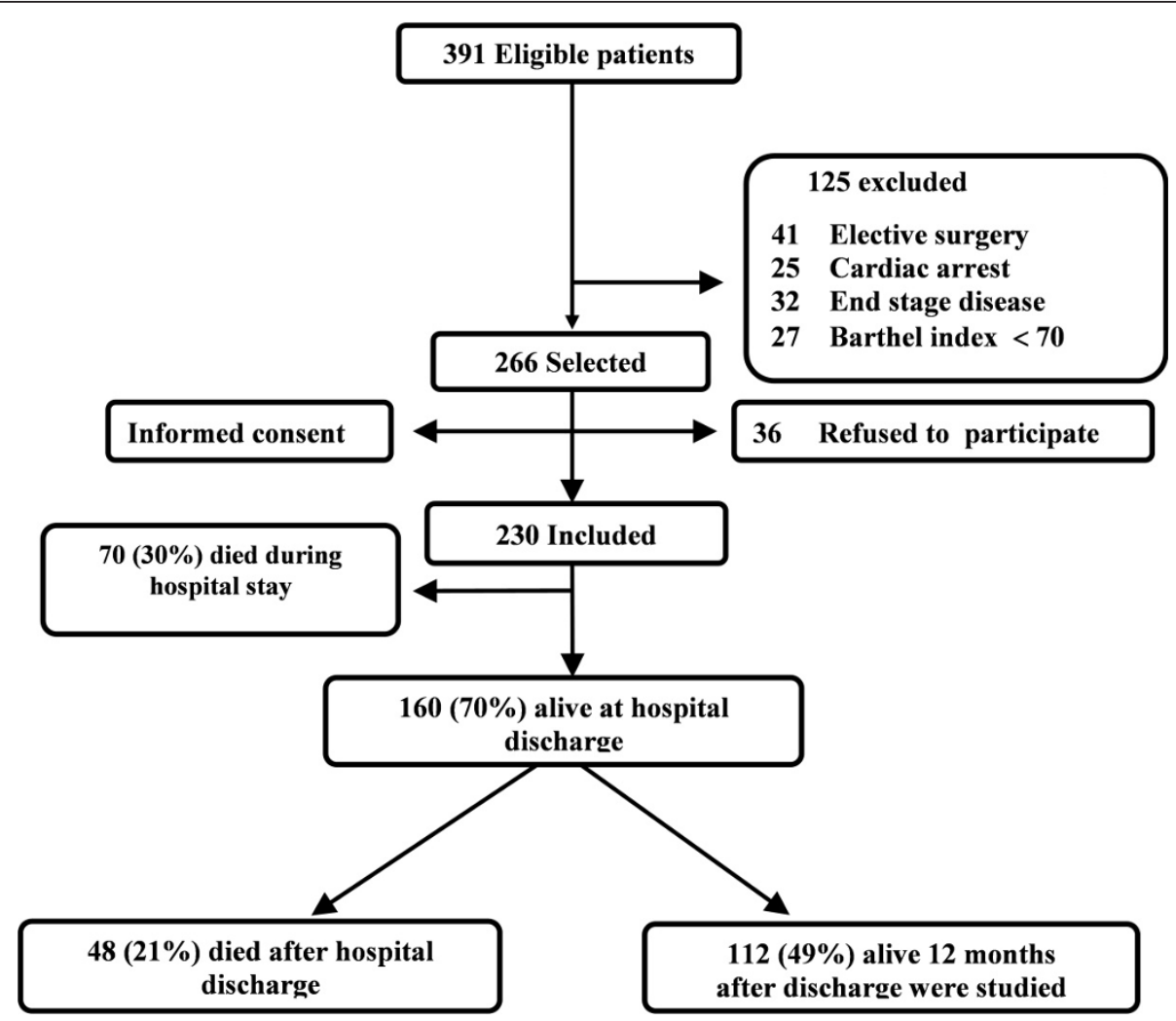

Figure 1 Flow Chart of the Patients Studied. Flow chart of the patients eligible for the study and those finally studied during follow-up.

(MMSE) when possible; the Charlson Index was used to evaluate comorbidity [22]. We considered the baseline status of the patient (in terms of functionality and quality of life) as the situation that the patient had before becoming ill and subsequently requiring ICU admission.

Finally, quality of life was measured using the EuroQol-5D (EQ-5D), a health status scale validated in critical patients in our country [23]. This scale evaluates five domains (mobility, self-care, usual activities, pain/disorder and anxiety/depression) and includes the EQ-5D index and the EQ-5D vas, a visual analogue scale ranging from 0 to 100 . All the scales were always completed by the patients. Nonetheless, a close relative was interrogated when the patient was unable to answer on the baseline visit. Concordance between self-administered and family member-administered scores was evaluated with the Kappa Index (KI). The KI was high (0.71 to 0.83 ) when mobility, personal care, usual activities and global health status (good vs. bad health) were evaluated, being slightly lower (0.55 to 0.62 ) when anxiety/depression or pain/discomfort was assessed.

\section{Follow-up studies}

The CGA evaluation was performed at baseline, at ICU and hospital discharge and also 3, 6 and 12 months after hospital discharge. On every scheduled appointment in our out-patient geriatric clinic a member of the geriatric team performed the CGA evaluation with the validated scales described above. Likewise, assessment of the incidence/prevalence of the main geriatric syndromes (urinary incontinence, faecal incontinence, depression, delirium, falls, immobility, cognitive impairment, polypharmacy and malnutrition) was also performed.

Good outcome was described as a decrease in the Lawton Index ( $\leq 2$ points) and/or Barthel Index $(\leq 20$ points) and/or EQ-5D vas ( $\leq 20$ points), compared to preICU status.

\section{Diagnostic criteria for main geriatric síndromes}

The term "geriatric syndrome" refers to common clinical conditions in older persons that do not fit into specific disease categories. Delirium (assessed by the Confusion Assessment Method score), falls (two or more in the last six months), immobility, pressure ulcers, malnutrition, cognitive impairment (abnormal scoring in MMSE or IQCODE), polypharmacy (4 $\geq$ drugs/day), depression (the Yesavage score was applied) [24] and urinary and or faecal incontinence are classified as geriatric syndromes. These conditions are 
highly prevalent and multifactorial and are associated with substantial morbidity, poor outcomes and worse quality of life in elderly subjects [25].

\section{Statistical analysis}

The data were analysed using SPSS-PC 16.0 statistical software (SPSS, Chicago, IL, USA). As almost all variables followed a normal distribution, variables were expressed as mean \pm standard deviation. For continuous variables paired or unpaired T-tests were used to compare differences between groups, whereas the chi-square and Fisher exact tests were used to compare dichotomous variables. In addition, we used an ANOVA for multiple comparisons when appropriate. A two-tailed $P$-value $<0.05$ was considered statistically significant. Forward multiple regression analysis (in: 0.05; out: 0.10) was performed in variables which were significant $(P \leq$ 0.1 ) on univariate analysis (age, length of ICU stay, BI, EQ-5D vas and geriatric syndromes at hospital discharge).

\section{Results}

\section{Demographic data}

The main features of the initial cohort $(n=230)$ were: mean age: $74.5 \pm 5.6$ years; APACHE score at ICU entry: $19.7 \pm 5.7$ points; mean ICU stay: $11.7 \pm 11.6$ days; 71 and $7 \%$ of patients underwent mechanical ventilation and haemodialysis, respectively; and hospital mortality (ICU + Ward) of 30\%. A detailed description of the baseline characteristics and mortality (in- and out-hospital) of the initial cohort has been published elsewhere [15].

Of the 160 patients alive after ICU care, 48 died during the following months after hospital discharge, thus only 112 subjects remained alive one year later. The mean age of this subcohort $(n=112)$ was $73.4 \pm 5.5$ years (range: 65 to 87 years), thus, 74 years was the cutoff point used to classify patients as young-old (65 to 74 years; $n=62$ patients, $55 \%$ ) and old-old ( $\geq 75$ years; $n=$ 50 patients, $45 \%)$. Ninety-eight percent of patients were living at home until the day prior to ICU admission.

\section{Baseline characteristics of the patients}

Table 1 shows the main baseline characteristics of the patients including ICU data and functional status prior to intensive care admission. The mean APACHE II at ICU entry was $19.2 \pm 6$ points (range 8 to 47 points) and the length of ICU stay was $9.4 \pm 10.2$ days (range 2 to 54 days). Mechanical ventilation and haemodialysis were applied in 54 and $4 \%$ of patients, respectively. All the patients showed an excellent baseline functional status evaluated by the Barthel and Lawton Indexes.

Table 1 Demographic, ICU and comprehensive geriatric assessment data at baseline

\begin{tabular}{|c|c|c|c|}
\hline & $\begin{array}{c}\text { Whole group } \\
\text { of patients } \\
(n=112)\end{array}$ & $\begin{array}{l}\text { Patients } 65 \text { to } 74 \text { years old } \\
(n=62)\end{array}$ & $\begin{array}{c}\text { Patients } \geq 75 \text { years } \\
(n=50)\end{array}$ \\
\hline$\overline{\text { Age }(y)}$ & $73.4 \pm 5.5$ & $69.3 \pm 2.8$ & $78.5 \pm 3.1$ \\
\hline $\operatorname{Sex}(M / F) \%$ & $57 / 43$ & $60 / 40$ & $54 / 46$ \\
\hline APACHE II at ICU admission & $19.2 \pm 6.0$ & $19.1 \pm 4.9$ & $19.2 \pm 7.1$ \\
\hline SOFA at ICU admission & $5.6 \pm 3.7$ & $5.7 \pm 3.9$ & $5.4 \pm 3.5$ \\
\hline Length of ICU stay (d) & $9.4 \pm 10.2$ & $10.7 \pm 11.9$ & $7.9 \pm 7.3$ \\
\hline Cardiac disease $\mathrm{n},(\%)$ & $13(12)$ & $5(10)$ & $8(16)$ \\
\hline Respiratory disease $n,(\%)$ & $49(44)$ & $23(37)$ & $26(52)$ \\
\hline Severe sepsis/septic shock n, (\%) & $23(20)$ & $14(23)$ & $9(18)$ \\
\hline Cerebrovascular disease n, (\%) & $13(12)$ & $9(14)$ & $4(8)$ \\
\hline Other medical disease $n,(\%)$ & $14(12)$ & $10(16)$ & $4(8)$ \\
\hline Mechanical ventilation $\mathrm{n},(\%)$ & $62(54)$ & $28(45)$ & $34(68)^{*}$ \\
\hline Haemodialysis/CWHDF n, (\%) & $4(3,6)$ & $1(1,6)$ & $3(6)$ \\
\hline OMEGA score & $115.3 \pm 122.8$ & $132.2 \pm 151.1$ & $95.3 \pm 74.1$ \\
\hline Lawton Index & $6.8 \pm 1.6$ & $7.2 \pm 1.4$ & $6.4 \pm 1.7^{*}$ \\
\hline Barthel Index & $96.4 \pm 8.7$ & $96.6 \pm 9.3$ & $96.1 \pm 7.9$ \\
\hline Charlson Index & $2.4 \pm 1.7$ & $2.2 \pm 1.6$ & $2.7 \pm 1.8$ \\
\hline$E Q-5 D$ vas & $76.1 \pm 16.4$ & $78.0 \pm 15.9$ & $73.2 \pm 16.8$ \\
\hline $\mathrm{EQ}-5 \mathrm{D}_{\text {index }}=11,111(\%)$ & 38 & 40 & 35 \\
\hline
\end{tabular}

$P<0.05$ vs. young-old patients.

Acute Physiology and Chronic Health Evaluation (APACHE).

Sepsis-related Organ Failure Assessment (SOFA).

Continuous venovenous haemodiafiltration: CVVHDF.

EuroQol-5D visual analogue scale: EQ-5D vasi EuroQol-5D index: EQ-5D index. 
Indeed, only $5 \%$ of patients had a basal Barthel Index $<85$ points. In addition, cognitive status assessed with the IQCODE was normal in $98 \%$ of the subjects whereas comorbidity was moderate. Older subjects had a slightly decreased Lawton Index compared to younger patients $(P=0.016)$ whereas women had a lower Charlson Index (Table 1).

The quality of life before ICU admission was good with no differences between younger and older subjects. Thus, three quarters of the patients had 70 or more points in the EQ-5D vas which is the level considered as good health. Up to $65 \%$ of the subjects had slight impairment in only one of the EQ-5D subdomains, being pain/discomfort (37.9\%) the most affected. Only $21 \%$ of subjects, especially the more elderly $(P=0.004)$, had two or more geriatric syndromes at baseline being polypharmacy, falls and depression the most prevalent. The presence of geriatric syndromes $(\geq 2)$ was directly associated with a lower perceived quality of life assessed by EQ-5D vas $(64.6 \pm 17.3$ vs. $79.7 \pm 15.6 ; P=0.002)$ and also with a worse functional status in IADL and ADL $P<0.05$, both).

\section{Functional status and quality of life during follow-up}

Autonomy in IADL was significantly decreased after discharge $(P<0.001)$ and the baseline situation in IADL was not recovered in the following 12 months $(6.7 \pm 1.7$ vs. $5.3 \pm 2.6$ points; $P<0.001$ ) (Figure 2). In fact, the previous Lawton Index was not achieved in up to $45 \%$ of the subjects at the end of the study period, with no significant differences between younger and older subjects. However, a significant decrease was observed in IADL autonomy (decrease in $\geq 2$ activities) in only $27 \%$ of patient whereas the IADL autonomy improved in $6 \%$. Likewise, the whole cohort (also both groups separately) showed a significant decrease in ADL autonomy $(96.3 \pm$ 8.8 vs. $69.8 \pm 29.2$ points $)$ at hospital discharge $(P<$ 0.001 both) which was not fully recovered in the following 12 months $(96.3 \pm 8.8$ vs. $87.1 \pm 22.8 ; P<0.001)$ (Figure 3). In fact, up to $37 \%$ of the patients did not achieve their previous Barthel Index at the end of the study period. However, a significant decrease in ADL autonomy (decrease in $\geq 20$ points in $\mathrm{BI}$ ) was only observed in $17 \%$ of patients whereas $11 \%$ of subjects improved. The patients who did not achieve full recovery were of 75 years of age or more ( 55 vs. $22 \%$; $P=$ 0.002). Maximal functional recovery was achieved in the first three to six months after discharge without additional improvement in the following six-month period and autonomy in IADL and ADL was similar in older and younger subjects at the end of the follow-up (Figures 2 and 3). Functional status (LI and BI) during posthospital follow-up was not significantly influenced by the main diagnosis at ICU entry or by the use of

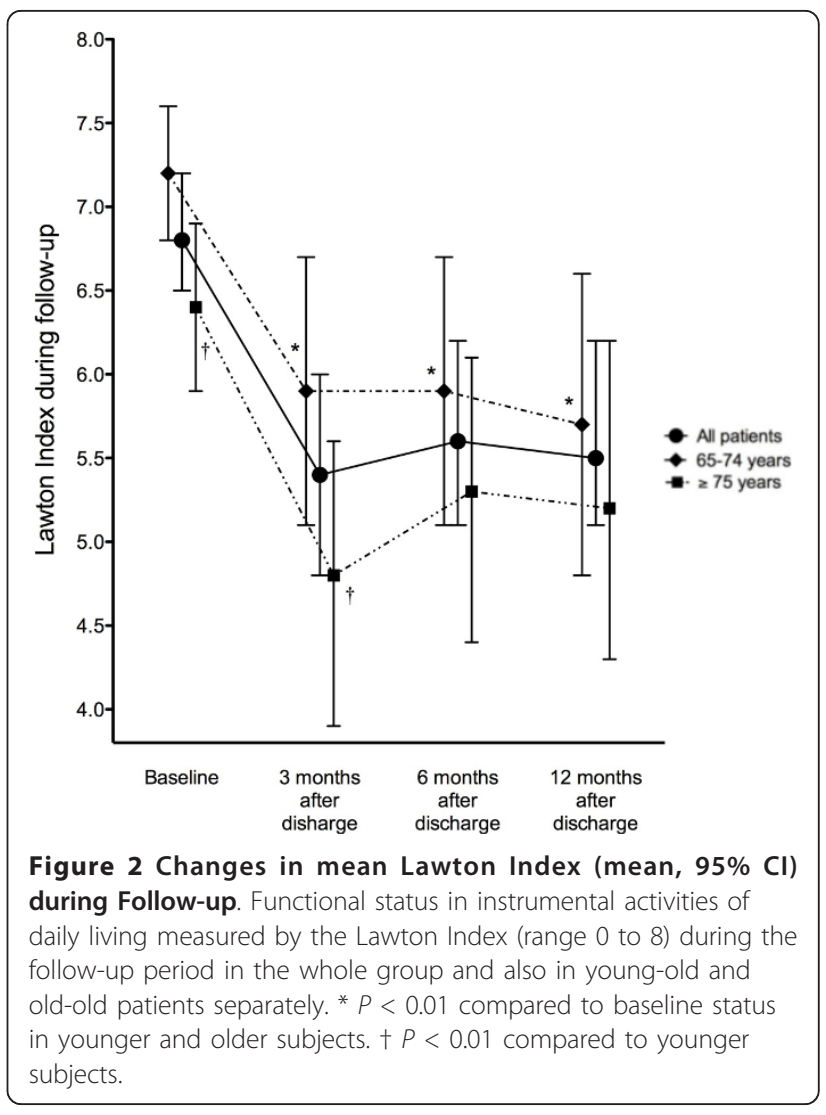

mechanical ventilation. However, patients with an OMEGA score greater than 67 (the $50^{\text {th }}$ percentile of the cohort) had a lower Barthel Index at hospital discharge and 3, and 12 months after discharge compared to those with an OMEGA score lower than $67(P<$ 0.05, all).

Cognitive Status was normal in $85 \%$ of the patients at hospital discharge whereas $15 \%(n=17)$ had a MMSE $<24$ points. One third did not recover during follow-up. At the end of the study, $10 \%$ of patients had a score lower than 24 in the MMSE, half of the patients had an abnormal MMSE score after hospital discharge and cognitive impairment developed during follow-up in the other half.

At hospital discharge the EQ-5D vas was significantly lower compared to baseline, $55.5 \pm 19.6$ vs. $76.1 \pm 16.4$ points $(P<0.001)$, and progressively improved in the following months. However, the EQ-5D vas remained lower than at baseline $(67.9 \pm 16.8$ vs. $76.1 \pm 16.4 ; P=$ 0.034 ) 12-months after discharge. Indeed, at the end of follow-up $61 \%$ of patients had a lower EQ-5D vas compared to that obtained at the beginning of the study, although a clinically relevant ( $\geq 20$ points) decrease in this score was only observed in a minority of the patients (31\%). In addition, we observed that only $18 \%$ of the subjects reported no disability in any EQ domains 12-months after discharge compared to $38 \%$ at baseline. 


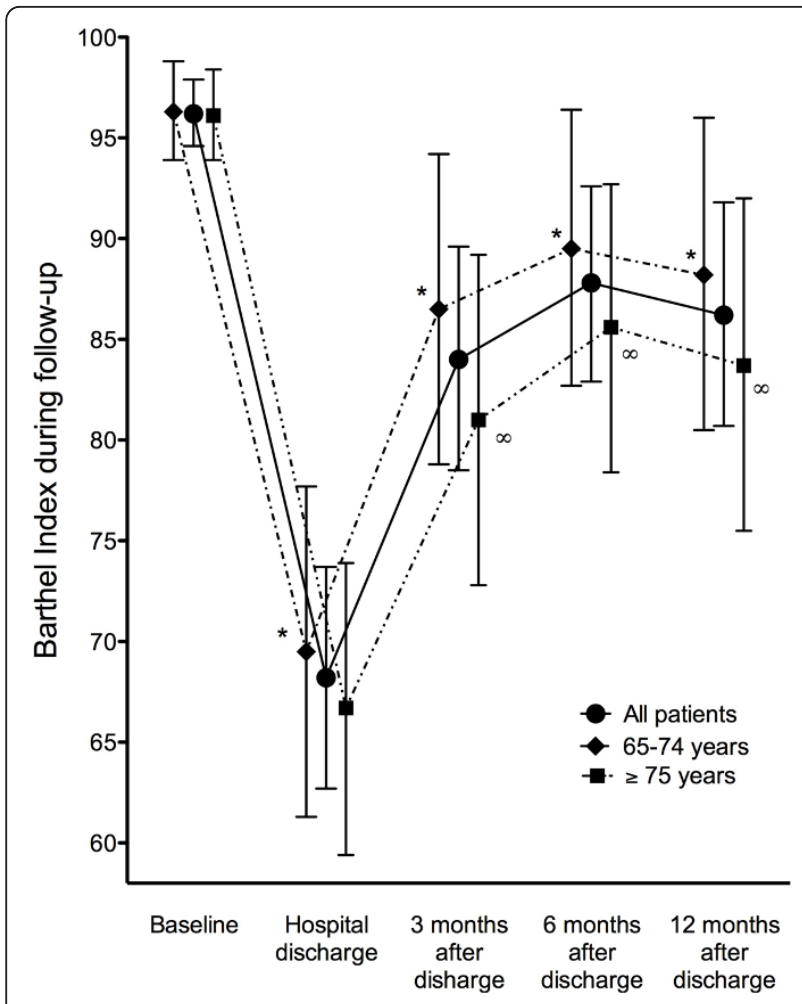

Figure 3 Changes in mean Barthel Index (mean, 95\% Cl) during follow-up. Functional status in basic activities of daily living measured by the Barthel Index (range 0 to 100) during the followup period in the whole group and also in young-old and old-old patients separately. ${ }^{*} P<0.01$ compared to baseline Bl (younger and older subjects). $\infty P<0.01$ compared to $\mathrm{Bl}$ at hospital discharge (younger and older subjects).

However, most of the disabilities (75\%) were of slight or moderate intensity. In fact, only $17 \%$ of the patients had a decrease of four or more points in EQ-domains whereas up to $83 \%$ of patients improved or had minor changes in EQ-domains during follow-up. Anxiety, pain and usual activities were the domains most frequently affected at the end of the study.

\section{Geriatric syndromes during follow-up}

The prevalence of subjects with $\geq 2$ geriatric syndromes increased immediately after ICU admission and up to 95\% at ICU discharge, and decreased slowly thereafter. Nonetheless, this prevalence remained higher 12-months after discharge $(37.2 \%)$ compared to baseline $(P<0.001)$ (Figure 4). Polypharmacy 70.8\%, urine incontinence 23\%, depression $18.8 \%$, immobility $16.7 \%$, faecal incontinence $13 \%$ and cognitive impairment $10 \%$ were the most frequent geriatric syndromes at the end of follow-up.

Finally, as expected, the QOL, IADL and ADL autonomy of the subjects with two or more geriatric syndromes was worse than those with less than two geriatric síndromes $(P<0.01$, all $)$.
Factors associated with good long-term outcome

Only 112 (48.7\%) of 230 patients of the initial cohort were alive 12 months after hospital discharge. In these 112 subjects, a higher Barthel Index $(P=0.001)$, higher EQ- $5 D_{\text {vas }}(P<0.03)$ and fewer geriatric syndromes at hospital discharge $(P<0.01)$ were predictors of full functional recovery in the following months (univariate analysis).

Thus, $71 \%$ of patients with a Barthel Index $\geq 60$ at hospital discharge achieved full recovery in ADL compared to $39 \%$ with a Barthel Index $<60(P=0.005)$. Subjects with a Barthel Index $\geq 60$ at hospital discharge had a hazard ratio for full functional recovery in ADL of 4.04 (95\% CI: 1.58 to $10.33 ; P=0.005$ ) compared to those with a lower Barthel Index at that time. On the other hand $69 \%$ of subjects with EQ-5D vas $\geq 40$ at hospital discharge achieved full recovery in IADL compared to $26 \%$ with an EQ-5D vas $<40(P<0.01)$. Thus, patients with EQ-5D $\mathrm{D}_{\text {vas }} \geq 40$ at hospital discharge had a hazard ratio for full recovery in IADL of 6.1 (95\% CI: 1.9 to $19.9 ; P<0.01]$. On multivariate analysis the predictive factor for full recovery in ADL and IADL was the Barthel Index and EQ-5D vas at hospital discharge, respectively (both, $P=0.001$ ).

\section{Patient death during post-hospital follow-up}

As shown in Figure 1, a group of patients ( $n=48$, mean age of $76 \pm 5$ years) died shortly after hospital discharge (median survival time: 45 days). These patients were significantly older $(P=0.006)$, more frequently mechanically ventilated ( 71 vs. $54 \% ; P=0.035$ ) and had a lower Lawton Index $(P=0.012)$, EQ-5D vas $(P=0.004)$ as well as a greater number of geriatric syndromes at baseline $(P=0.019)$ compared to patients with a long-survival time. However, no differences were observed in ICU scores (APACHE, SOFA and OMEGA), length of ICU

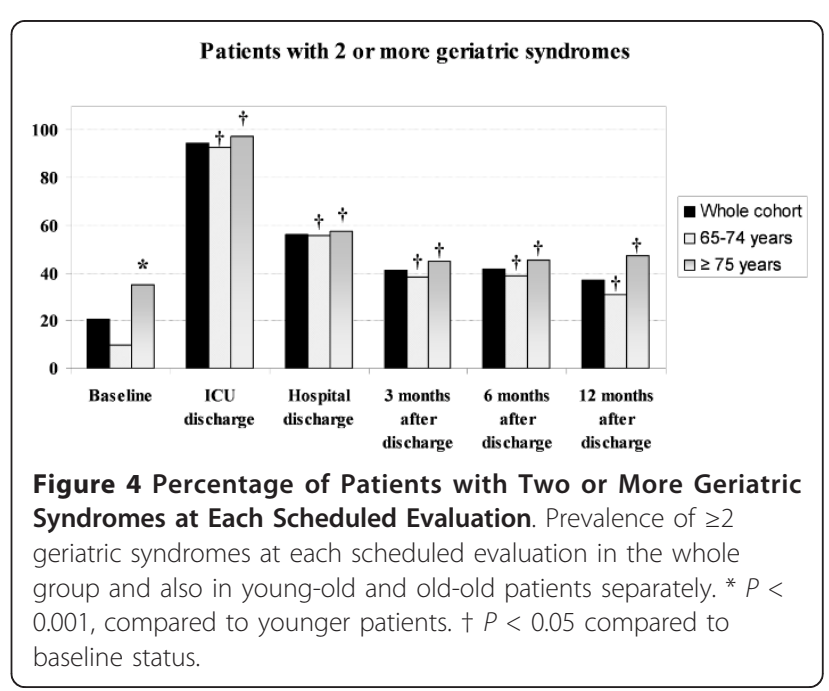


stay, Charlson Index, main diagnostic categories at ICU entry and the Barthel Index at ICU admission and at hospital discharge between the two groups.

\section{Discussion}

Healthy elderly patients have a low survival rate 12 months after discharge from a medical ICU. In patients who survive at least one year, more than two thirds have a similar functional autonomy and quality of life compared to baseline, although there is a two-fold increase in the prevalence of the main geriatric syndromes. Functional status (Barthel Index) and quality of life (EQ-5D) at hospital discharge are the best predictive factors for full functional recovery at long-term follow-up.

The elderly population is growing in the ICUs in Western countries with patients aged 75 or more years representing 20 to $25 \%$ of the total ICU patients at the beginning of the 21 st century compared to $12 \%$ in the late 1990s [1,2,5]. A recently published study performed in Australia and New Zealand calculated a potential increase of $72 \%$ in ICU demand for patients older than 80 years between 2005 to 2015 [26]. Consequently, it is of great interest to know the outcomes of these old and very old patients after ICU care $[1,2,5,7,27,28]$. Some studies have demonstrated that although mortality is high (up to $60 \%$ one year after discharge), age itself it is not an independent risk factor for mortality $[1,5,15]$. Recently, in addition to mortality, other parameters such as functional status and quality of life after ICU discharge have also been evaluated $[3,8,9,11,27,29]$. However, most of these studies are mainly restricted to surgical patients, whereas medical patients are scarcely represented. Indeed, one study suggested that a medical condition is an independent factor for ICU refusal in patients aged 80 years or more [3]. Therefore, most published reports have a low proportion of medical patients, thereby making it difficult to achieve conclusions about the long-term outcomes of this specific group of elderly patients after ICU care.

In a small sample $(n=32)$ of medical patients Chelluri et al. [29] observed that $84 \%$ of patients independent for ADL prior to ICU entry maintained this situation whereas the quality of life improved slightly one year later. Montuclard [8] evaluated 28 medical patients $\geq 70$ years with a long ICU stay ( $\geq 30$ days) several months after discharge and observed increased dependence in some ADL (bathing, dressing, toileting, transfer and continence) and decreased quality of life in specific domains (global health, memory, sociability, leisure), in spite most of the patients remaining independent. In another study, Garrouste-Orgeas [3] evaluated 48 patients older than 80 years and observed no differences in ADL before and after ICU stay, although the quality of life was significantly worse in some domains (isolation, emotion, mobility) compared to a matched population. Kaarlola [9] evaluated a larger sample $(n=299)$ with a mailed-QOL questionnaire and detected that $88 \%$ of elderly survivors assessed their post ICU health status as good or satisfactory, 53\% needed no assistance and one-third lived alone at home. Finally, De Rooij et al. [11] concluded that long-term elderly survivors after ICU care showed fair to good cognitive, functional and QOL status. However, only $5 \%(n=11)$ of these subjects were medical patients and the ICU stay was too short ( $<5$ days in $88 \%$ of patients). The main limitations of these studies were the sample size, retrospective data collection, absence of functional and QOL evaluation prior to ICU entry, high variability in demographic context and, in some instances, the use of non-validated scales to assess the functionality and quality of life of the subjects.

To avoid the limitations described above we have selected a well defined population of healthy community-dwelling elderly patients prior to ICU entry who required critical care for a medical condition and were alive one year after discharge.

We observed a low survival rate (49\%) 12 months after discharge in this population, although the survivors had a relatively good health status in terms of functional and cognitive status as well as in the perceived quality of life. In this sense, $73 \%, 83 \%$ and $69 \%$ of patients showed similar scores in IADL and ADL autonomy and quality of life evaluation, respectively, compared to pre-ICU status. Interestingly, only one quarter of the patients with a Barthel Index lower than 50 at hospital discharge reached full recovery one year later. However, a major concern in these patients is the two-fold increase in the prevalence of main geriatric syndromes (mainly polypharmacy, urinary incontinence and depression) even at long-term follow-up that obviously reduced the perceived quality of life. On the other hand, patients with a short survival time (less tan one year) after ICU care were older, more frequently required mechanical ventilation and had worse scores at baseline (Lawton Index and EQ-5D vas) and also had more geriatric syndromes at baseline compared to patients with a long survival time. No differences were detected between the two groups in ICU scores, comorbidity, length of ICU stay and the main diagnoses at ICU admission or in functional status (Barthel Index) at hospital discharge. Our results firmly suggest that pre-clinical frailty before ICU care defined as a lower score in the Lawton Index may be a good marker to identify a population with a high risk of bad outcome after discharge.

Some mandatory questions arise from the present data: Is it possible to improve the outcomes of these elderly survivors after ICU care?, Could we introduce 
changes (for example: systematic multidisciplinary management) in the post-ICU follow-up of elderly patients to achieve better results?, Which subpopulation of medical elderly patients could benefit from specific interventions to improve outcomes after ICU care?

Only a recent study by Somme et al. [30] has tried to answer some of these questions. In a well designed prospective randomised clinical trial they compared the benefits of "geriatric care" versus "standard care" in the management of a small sample $(n=45)$ of subjects greater than 75 years old surviving a medical ICU admission. The main results showed no significant differences in the two study groups, although the outcomes in the "geriatric care cohort" were slightly better six months after discharge. However, these negative results must be considered with caution because the sample studied was very small and did not have enough statistical power, as was pointed out by the authors [30].

Our manuscript has several strengths such as the prospective enrolment of the subjects, long-term follow-up, inclusion of only medical patients with a good baseline health status and finally, the use of validated geriatric scales to objectively assess patient status. On the other hand, the main limitation is that the results can not be extrapolated to all elderly patients admitted to the ICU because we selected only medical patients with a good health status prior to ICU entry. Indeed, one third of the elderly patients admitted to our ICU did not fulfill the inclusion criteria and were excluded. Although our sample is not very large, it is quite homogeneous and representative of healthy community-dwelling elderly patients with a theoretical long life-expectancy before ICU admission and also with the best chance of survival to ICU care. Patient outcomes would probably be worse in a non-selected elderly population.

\section{Conclusions}

In summary, in a well-selected population of healthy elderly people prior to critical care admission the expected outcomes in terms of survival 12 months after medical ICU discharge are bad because the mortality may be up to $51 \%$ of the subjects. However, the functional autonomy, cognitive status and quality of life were apparently good in the survivors, although a great increase in the prevalence of geriatric syndromes was observed. As a reflection of these results, most of the survivors $(74 \%)$ would accept readmission to the ICU if necessary. It remains to be elucidated whether changes in the post-ICU management of these patients could improve their outcomes.

\section{Key messages}

- Outcomes of previously healthy elderly patients after non-elective medical ICU admission were bad (one-year mortality was 50\%, whereas functional autonomy and quality of life were significantly lower compared to baseline).

- A two-fold increase in geriatric syndromes after ICU care was observed.

- A Barthel Index ( $\geq 60)$ or EQ-5D vas $(\geq 40)$ at hospital discharge were associated with full-functional recovery in most of the patients.

- It remains to be elucidated whether changes in the post-ICU management of these patients could improve their outcomes.

\section{Abbreviations}

ADL: Activities of Daily Life; APACHE III: Acute Physiology and Chronic Health Evaluation III; BI: Barthel Index; CGA: Comprehensive Geriatric Assessment; CWHDF: continuous venovenous haemodiafiltration; EQ-5D: EuroQol-5D; EQ5D vas: Visual analogic scale of EuroQol-5D; IADL: Instrumental Activities of Daily Life; ICU: intensive care unit; IQCODE: Informant Questionnaire on Cognitive Decline in the Elderly; KI: Kappa Index; LI: Lawton Index; MMSE: minimental status evaluation; QOL: quality of life; SOFA: Sepsis-related Organ Failure Assessment.

\section{Acknowledgements}

The funding came from a grant by the Fondo de Investigación Sanitaria (FIS) (PI:03/0329) and Centro de Investigación Biomédica en Red (CIBER) 06/003: Fisiopatología de la Obesidad y Nutrición, Instituto de Salud Carlos III. The funding agency has no role in the interpretation or presentation of the data. In addition, no author has received reimbursements, fees, funding, or a salary for this study.

\section{Author details}

'Geriatric Unit, Department of Internal Medicine Hospital Clínic of Barcelona, Villarroel, 170, Barcelona 08036, Spain. ${ }^{2}$ Institut d'Investigacions Biomèdiques August Pi i Sunyer (IDIBAPS), Faculty of Medicine, University of Barcelona, Casanova 143, Barcelona 08036, Spain. ${ }^{3}$ Intensive Care Unit, Department of Internal Medicine Hospital Clínic of Barcelona, Villarroel, 170, Barcelona 08036, Spain.

\section{Authors' contributions}

ES, JMN and AL-S contributed to study conception and design. PC and JMN contributed to recruitment and follow-up of the patients during their ICU stay. JMP-C, FM and MN contributed to recruitment and follow-up of the patients after their ICU stay. ES and JMP-C contributed to introduction of collected data in SPSS file for analysis. ES, JMN and AL-S contributed to analysis and interpretation of the data. ES, JMP-C and AL-S contributed to drafting of the article. ES, JMP-C, JMN, FM, MN, PC and AL-S contributed to critical revision and final approval of the manuscript.

\section{Competing interests}

The authors declare that they have no competing interests.

Received: 16 September 2010 Revised: 23 December 2010 Accepted: 28 March 2011 Published: 28 March 2011

\section{References}

1. Boumendil A, Somme D, Garrouste-Orgeas M, Guidet B: Should elderly patients be admitted to the intensive care unit? Intensive Care Med 2007, 33:1252-1262.

2. Pisani MA: Considerations in caring for the critically ill older patient. J Intensive Care Med 2009, 24:83-95.

3. Garrouste-Orgeas M, Timsit JF, Montuclard L, Colvez A, Gattolliat O, Philippart F, Rigal G, Misset B, Carlet J: Decision-making process, outcome, and 1-year quality of life of octogenarians referred for intensive care unit admission. Intensive Care Med 2006, 32:1045-1051.

4. Boumendil A, Aegerter P, Guidet B, CUB-Rea Network: Treatment intensity and outcome of patients aged 80 and older in intensive care 
units: a multicenter matched-cohort study. J Am Geriatr Soc 2005, 53:88-93.

5. Hennessy D, Juzwishin K, Yergens D, Noseworthy T, Doig C: Outcomes of elderly survivors of intensive care: a review of the literature. Chest 2005, 127:1764-1774.

6. de Rooij SE, Govers A, Korevaar JC, Abu-Hanna A, Levi M, de Jonge E: Short-term and long-term mortality in very elderly patients admitted to an intensive care unit. Intensive Care Med 2006, 32:1039-1044.

7. Ely EW: Optimizing outcomes for older patients treated in the intensive care unit. Intensive Care Med 2003, 29:2112-2115.

8. Montuclard L, Garrouste-Orgeas M, Timsit JF, Misset B, de Jonghe B, Carlet J: Outcome, functional autonomy, and quality of life of elderly patients with a long-term intensive care unit stay. Crit Care Med 2000 28:3389-3395.

9. Kaarlola A, Tallgren M, Pettilä V: Long-term survival, quality of life, and qualityadjusted life-years among critically ill elderly patients. Crit Care Med 2006, 34:2120-2126.

10. Rellos K, Falagas ME, Vardakas KZ, Sermaides G, Michalopoulos A: Outcome of critically ill oldest-old patients (aged 90 and older) admitted to the intensive care unit. J Am Geriatr Soc 2006, 54:110-114.

11. de Rooij SE, Govers AC, Korevaar JC, Giesbers AW, Levi M, de Jonge E: Cognitive, functional and quality of life outcomes of patients aged 80 and older who survived at least 1 year after planned or unplanned surgery or medical intensive care treatment. J Am Geriatr Soc 2008, 56:816-822.

12. Wunsch H, Guerra C, Barnato AE, Angus DC, Li G, Linde-Zwirble WT: Threeyear outcomes for Medicare beneficiaries who survive intensive care. JAMA 2010, 303:849-856.

13. European Health expectancy monitoring units (EHEMU). [http://www. ehemu.eu/pdf/CountryReports_Issue3/Spain.pdf].

14. Lerolle N, Trinquart L, Bornstain C, Tadié JM, Imbert A, Diehl JL, Fagon JY, Guérot E: Increased intensity of treatment and decreased mortality in elderly patients in an intensive care unit over a decade. Crit Care Med 2010, 38:59-64.

15. Sacanella E, Pérez-Castejón JM, Nicolás JM, Masanés F, Navarro M, Castro P, López-Soto A: Mortality in healthy elderly patients after ICU admisión. Intensive Care Med 2009, 35:550-555.

16. Demoule A, Cracco C, Lefort $Y$, Ray P, Derenne JP, Similowski T: Patients aged 90 years or older in the intensive care unit. $J$ Gerontol A Biol Sci Med Sci 2005, 60:129-132.

17. Knaus WA, Draper EA, Wagner DP, Zimmerman JE: APACHE II: a severity of disease classification system. Crit Care Med 1985, 13:818-829.

18. Vincent JL, Moreno R, Takala J, Willatts S, De Mendonça A, Bruining H, Reinhart CK, Suter PM, Thijs LG: The SOFA (Sepsis related organ failure assessment) score to describe organ dysfunction/failure On behalf of the Working Group on Sepsis-Related Problems of the European Society of Intensive Care Medicine. Intensive Care Med 1996, 22:707-710.

19. Societé de Reanimation de Langue Française: Utilisation de l'indice de gravité simplifié et du système oméga: Mise à jour 1986. Réanimation Soins Intensifs Médecine Urgences 1986, 2:219-221.

20. Lawton MP, Brody EM: Assessment of older people: self-maintaining and instrumental activities of daily living. Gerontologist 1969, 9:179-186.

21. Mahoney FI, Barthel DW: Functional evaluation: the Barthel Index. Md State Med J 1965, 14:61-65.

22. Charlson ME, Pompei $P$, Ales $K L$, Mackenzie $C R$ : A new method of classifying prognostic comorbidity in longitudinal studies: development and validation. J Chronic Dis 1987, 40:373-83.

23. Badía X, Diaz-Prieto A, Górriz MT, Herdman M, Torrado H, Farrero E, Cavanilles JM: Using the EuroQol-5D to measure changes in quality of life 12 months after discharge from an intensive care unit. Intensive Care Med 2001, 27:1901-1907.

24. Yesavage JA: Depression in the elderly. How to recognize masked symptoms and choose appropriate therapy. Postgrad Med 1992 91:255-258, 261.

25. Inouye SK, Studenski S, Tinetti ME, Kuchel GA: Geriatric syndromes: clinical, research, and policy implications of a core geriatric concept. J Am Geriatr Soc 2007, 55:780-791.

26. Bagshaw SM, Webb SAR, Delaney A, George C, Pilcher D, Hart GK, Bellomo R: Very old patients admitted to intensive care in Australia and New Zealand: a multi-centre cohort analysis. Critical Care 2009, 13:R45.
27. Tabah A, Philippart F, Timsit JF, Willems V, Français A, Leplège A, Carlet J, Bruel C, Misset B, Garrouste-Orgeas M: Quality of life in patients aged 80 or over after ICU discharge. Crit Care 2010, 14:406.

28. Angus DC, Carlet J: 2002 Brussels Roundtable Participants: Surviving intensive care: a report from the 2002 Brussels Roundtable. Intensive Care Med 2003, 29:368-377.

29. Chelluri L, Pinsky MR, Donahoe MP, Grenvik A: Long-term outcome of critically ill elderly patients requiring intensive care. JAMA 1993, 269:3119-3123.

30. Somme D, Andrieux N, Guerot E, Lahjibi-Paulet H, Lazarovici C, Gisselbrecht M, Fagon JY, Saint-Jean O: Loss of autonomy among elderly patients alter a stay in a medical intensive care unit (ICU): A randomized study of the Benedit of transfer to a geriatric ward. Arch Gerontol Geriatr 2010, 50:e36-40

doi:10.1186/cc10121

Cite this article as: Sacanella et al:: Functional status and quality of life 12 months after discharge from a medical ICU in healthy elderly patients: a prospective observational study. Critical Care 2011 15:R105.

\section{Submit your next manuscript to BioMed Central and take full advantage of:}

- Convenient online submission

- Thorough peer review

- No space constraints or color figure charges

- Immediate publication on acceptance

- Inclusion in PubMed, CAS, Scopus and Google Scholar

- Research which is freely available for redistribution

Submit your manuscript at www.biomedcentral.com/submit
C Biomed Central 